\title{
Research on Cultivation of Translation Ability and College English Teaching
}

\author{
Changjie Wang \\ Foreign Languages Department, Sichuan University of Media and Communications, Chengdu \\ 611745, China
}

Key words: translation ability; English teaching; college English

\begin{abstract}
The cultivation of translation ability is an important part of non-English major college English teaching system. In recent years, the main reason for the relatively weak translation ability of college graduates is that the cultivation of translation ability in college English teaching couldn't attract enough attention. This paper analyzes the current situation of the cultivation of translation ability in college English teaching, and discusses the effective methods of cultivating students' translation ability. Finally, this paper expounds the concrete methods of cultivating translation ability in classroom teaching.
\end{abstract}

\section{Introduction}

With the frequent development of economic cooperation and the cultural exchanges between China and the world, the needs of foreign language professionals are more prominent. The translation cooperation and exchange is also very important as the bridge. A certain degree of translation is undoubtedly of great benefit for non-English majors college students who will work in various fields and industries[1]. Nowadays, translation teaching has not received in college English teaching, and translation teaching is generally based on teaching translation which lacks of translation theory and a variety of translation techniques and methods, as well as translation practice system translation teaching. However, the demand for science and technology translators is greatly increased. A few foreign language graduates have been unable to meet the social needs. Therefore, the cultivation of college students' English teaching ability can not be neglected.

The ability to translate is an important part of the target system of college English teaching, which is both an oral and written form of reading comprehension and ability to listen, speak and write. The translation ability is always carried out as an integral part of the whole English teaching process. This is closely linked to the understanding and expressing the content of a non-soil culture, historical phenomenon and its background material from the local perspective. Moreover, the process of understanding is often manifested through visual, auditory, or hints, and the expression is done through verbal, behavioral or written forms[2-4]. Therefore, the translation process is actually running through the renovation of English teaching. From this point, the cultivation of translation ability is a comprehensive embodiment of the English teaching quality.

In addition, the translation ability mainly refers to one kind of cultural and historical phenomenon and its background material or oral content is expressed accurately with another corresponding expression. It is common to say that English-Chinese translation, especially the written translation, belongs to this situation[5]. Therefore, the ability of English-Chinese translation is actually based on a profound understanding of the Anglo-American social and cultural background. In fact, English listening, speaking, reading and writing have a main body of the translation process throughout them. In this sense, the cultivation of translation ability in college English teaching is directly or indirectly related to other teaching contents untranslated. It has a very important position in the whole college English teaching. If one can not translate when learning English, he couldn't learn English well. This can also reflect that the cultivation of translation ability plays a great role in English teaching. 


\section{Status of cultivation of translation ability and college English teaching}

For a long time, English translation teaching has been "deserted", and translation failed to occupy a place in listening, speaking, reading, writing and translation skills. Although the translation examinations have been contained in the current CET 4\&6, teachers and students still can not give a high degree of attention to translation because of the small scores[6]. Besides, English class hour is limited, so it is impossible to set up a separate translation class for college English teaching. Many teachers only pay attention to listening, speaking, reading and writing and take no account into the cultivation of students' ability to translate. Even if there is sonsideration for translation , teachers can not give students a more systematic introduction to some common sense of translation skills owing to the unguranteed time. Finally, this results in the Chinese-English translation.

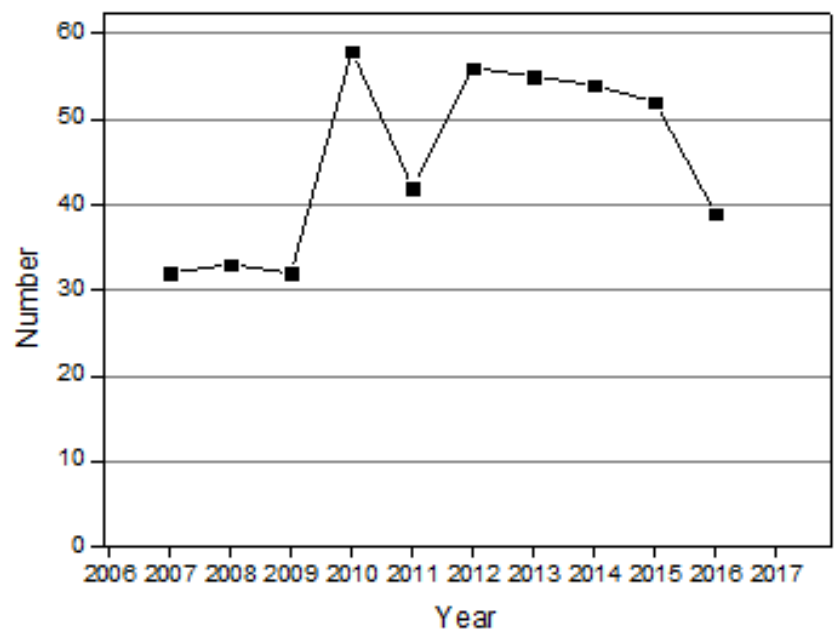

Figure 1. The statistical data about published papers about translation teaching from 2007 to 2016

At present, college English translation teaching is still confined to the traditional teaching mode in some colleges and universities offering college English translation courses. Teachers are in the dominant teaching position in the classroom, and the traditional teaching methods are adopted. Unfortunately, these tranditional teaching methods blindly instill the course content, and students are blindly accepted. There is little chance of translation practice in the classroom or in the real context. In the traditional teaching mode, students spend a lot of effort on the basis of the words which is good for laying a solid foundation of language knowledge and promoting the role of the higher level reading. But the active participation of students initiative is ignored[6, 7]. Figure 1 shows the papers trend about the tranlation research. Over time, teachers teach the rigid and boring teaching content which it is difficult to achieve effective teaching results, and is not conducive to the cultivation of students' ability to translate.

Table 1 The reaearch status about the published papers related translation teaching

\begin{tabular}{|c|c|c|c|}
\hline Journal & Number & Journal & Number \\
\hline Chinese Translators Journal & 132 & Foreign Languages Research & 14 \\
\hline Shanghai Translators Journal & 68 & FLLTP & 14 \\
\hline Language world & 67 & Foreign Languages Research & 10 \\
\hline $\begin{array}{c}\text { Foreign Languages and Their } \\
\text { Teaching }\end{array}$ & 28 & Foreign Languages & 2 \\
\hline Foreign Language Teaching & 25 & The Journal of Specialised Translation & 13 \\
\hline $\begin{array}{c}\text { Chinese sci-tech translator } \\
\text { Journal }\end{array}$ & 25 & ISSCI & 23 \\
\hline $\begin{array}{c}\text { Shandong Foreign Languages } \\
\text { Teaching Journal }\end{array}$ & 17 & Modern Foreign Languages & 1 \\
\hline Total & 439 & & \\
\hline
\end{tabular}


In the practice of English translation, students often encounter related knowledge background, such as English saying, social customs, historical events, life knowledge and other issues. And we are now isolatedly teaching a foreign language and ignoring the target language of the national culture. Besides, teachers rarely guide students to carry out the relevant cultural content of learning. Students are often make a lot of jokes when engaging in translation exercises, due to the lack of understanding of the target language culture of the country. The ultimate goal of language learning is to be able to communicate with others, and if the target language of the country's cultural performance is extremely strange, it will certainly cause some obstacles to communication.

\section{Translation methods in English teaching}

\subsection{The PACTE model}

The PACTE model whose full name is Process in the Acquisition if Translation Competence and Evaluation, is based on the concept of translation competence. This concept will pay more attention on the capability of transferring information between the native language and the targeted language which means if someone can speak two different languages, he can translate. Under the guidance of Wilss' theory, smooth translation is not supposed to be correct in grammar[8]. The ultimate goal of PACTE's research on translation skills is to conduct empirical studies on translation skills acquisition. The model of translation competence in 1998, research members have paid attention to the learning process and suggested that translation skills acquisition is a process of reorganizing and cultivating translator abilities. In 2003, PACTE researchers described the translation process more detailed, and proposed a relatively complete model of translation learning, which provided the direction for the translation teaching and the translator's ability to cultivate. PACTE pointed out that translation skills acquisition is a dynamic and spiral process which is similar to all learning processes, they developed from noviceknowledge to expertknowledge. Translation ability is composed of interrelated sub-abilities and the acquisition of translation ability aimed to build new knowledge on the basis of old knowledge. In this process, the most important thing is how to reorganize the existing knowledge.

The specific work is hypothetical: 1) The development and reorganization of translation capacity is the core of translation skills acquisition. 2) The acquisition and development of strategic competence is particularly important for the development and reorganization of other sub-abilities. 3) The development of specific learning strategies is the development and reorganization of others. 4) The development and reorganization of other sub-abilities are influenced by the following factors: translation direction, language composition, field of expertise or learning conditions. Learning process is very important to the acquisition process, because the process of translation skills acquisition is actually that the learners master the learning strategy or the ability to develop the strategy of the process. Figure 2 is the illustration of the PACTE translation model.

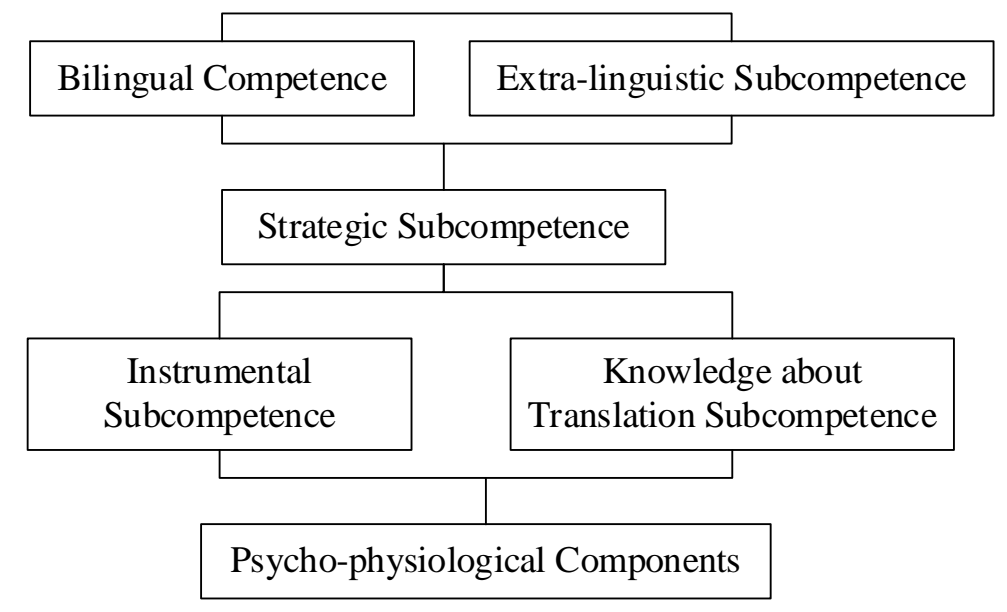

Figure 2. The PACTE translation model 


\subsection{The five-ring model in translation teaching}

The concept of translation teaching is the soul of translation teaching, and the comprehensive implementation of teaching content, methods and means is the specific content of translation teaching. Similarly, students get the translation concept to cultivate their ability to form the translate thinking and decision-making ability., whether it is teaching or learning, the goal of translation teaching is to develop students' translation ability. The five rings model employed in translation teaching is to achieve this goal from the overall design.

In translation teaching process, the five rings model can be simplified as bilingual reading and translation theory material reading, bilingual weekly writing, discourse translation exercises, small essay writing, job commentary, classroom content new grant and other aspects of the system. It emphasizes the whole translation of the curriculum teaching and learning activities and the spirit of its teaching is the organic combination of the open translation theory research results and translation practice. The mode of operation is the multi-directional interaction between teachers and students to cultivate students' translation concepts. The model is open, and its characteristics are the combination of classroom teaching and classroom teaching activities, curriculum teaching materials, flexible teaching methods. Teaching management is free and easy, teaching goal orientation is effective unity between the translation thought and the translation practice. Figure 3 shows the five-ring model. The five rings constitute the interaction links between teachers and students, and each link represents the specific content.

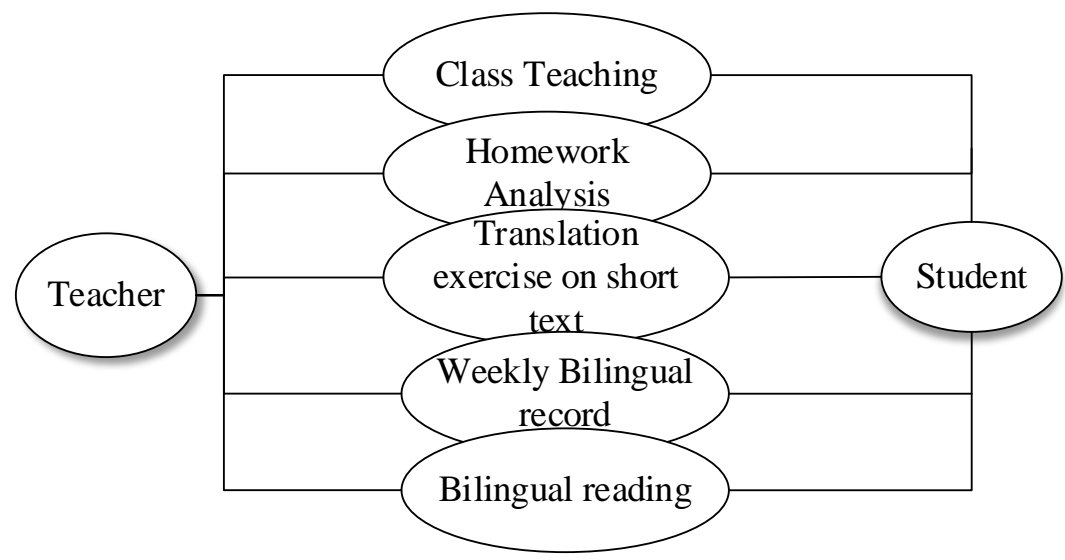

Figure 3 The five-ring model in translation teaching.

\section{The specific stactics of cultivating translation ability in college English teaching 4.1 Focus on language and culture contrast}

At present, the national college of non-English majors did not set up translation classes. But if some translation of knowledge and skills, and analysis of examples are contained in classroom teaching, students will certainly improve the translation ability. The specific approaches are as follows. First, contrastive knowledge in English and Chinese is the basis of translation. In the intensive teaching, teachers can choose typical examples, and analyze the original and translation in depth, so students will not only see the differences between English and Chinese forms, but also understand the intrinsic differences between the two languages and their cultural origins. In this way, they will know the translation and the reasons to improve the quality of translation. Similarly, teachers can also use examples to let students understand other differences between English and Chinese, such as differences between body type and object type and specific and abstract differences and so on.

\subsection{Strengthen translation skills}

On the basis of the students' understanding of the characteristics and differences of English and Chinese, it is necessary to strengthen the explanation and training of translation skills to help students grasp the law of translation and improve the translation ability. For example, according to the 
characteristics of Chinese and English, students are allowed to practice the translation of long English sentences. On the basis of understanding English abstract and Chinese language, students can practice the English abstract nouns into Chinese verbs in certain sentences. In the intensive reading of the text, teachers can choose a typical example to focus on a translation skills, and provide relevant exercises. So students practice to consolidate the skills. For some key translation techniques, such as word class conversion method, word addition and omission, translation of attributive clauses, translation of adverbial clauses, translation of noun clauses, translation of long sentences and translation of passive sentences, repeated explanation and training should be performed until students have mastered. There are many English-Chinese translation skills involved in the translation of the text. Teachers can also explain the relevant Chinese-English translation skills, or explain some important Chinese-English translation skills.

\subsection{Pay attention to the role of translation method in classroom teaching}

In college English teaching, it is certainly not advisable to use native language translation. In fact, in the teaching process of language knowledge, translation can not be ignored. And the appropriate use of native language translation method will promote effective teaching of English teaching means. Teaching translation is different from the general literary translation, and also the purpose and the object is not the same. The use of translation in college English teaching can help students to understand language, accept language information, and understand the language and cultural connotation and differences.

\section{Summary}

Translation is one of the most effective activity to reflect the use of language integrated activities. In order to cultivate students' practical ability to use English, we must pay more attention to the translation from the point of the teaching thought. Translation teaching will be organically integrated into the college English classroom teaching process for teaching classes lack translation training, and this not only can improve the quality of teaching, but also can cultivate and train students' translation ability, so that students comprehensive use of English ability is improved greatly.

\section{References}

[1] Bygate M, Swain M, Skehan P. Researching pedagogic tasks: Second language learning, teaching, and testing[M]. Routledge, 2013.

[2] Samad F. The Correlation Between Grammar Mastery and Translation Ability at Seventh Semster Students of English Education Study Program, Khairun University of Translate[J]. Edukali, 2016, 14(2).

[3] Zhu L. The relevance study of college students' chunk level and their translation ability[J]. Theory and Practice in Language Studies, 2014, 4(1): 181.

[4] Hu N, Xu X. Implications of Output Hypothesis in College English Translation Course[J]. 2015.

[5] Peng L, Tan X, Xie F. Rethinking the way out for College English teaching-After China's reform in national college entrance exam in English[J]. Journal of Language Teaching and Research, 2014, 5(6): 1393-1398.

[6] Siyuan L, Qijin W. Translation Teaching and Research in the 21st Century [J]. CHINESE TRANSLATORS JOURNAL, 2000, 1: 008.

[7] Beeby A, Fernández M, Fox O, et al. Results of the validation of the PACTE Translation Competence model: Translation project and dynamic translation index[J]. Cognitive Explorations of Translation. Londres \& Nueva York: Continuum Studies in Translation, 2011: 30-53. 